\title{
6. Looking Up, Looking Down: A New Vision in Motion
}

\author{
Jennifer Pranolo
}

\begin{abstract}
This article traces a genealogy of what it means to 'see' photographically. Turning to the eye exercises and perspective games of the educator László Moholy-Nagy, the psychologist Adelbert Ames, Jr., and the artist Elad Lassry, it focuses on the human body as a site of instability in exposing the hidden potentialities of photographic space. The camera and the photograph are not used to replicate a pre-existing vision of reality but to explore the visual and cognitive terrain of a new spatial logic. By examining how bodies are organized within and by the picture, it argues that the synthetic topologies of photographic seeing can proprioceptively reorient viewers to the heightened ambiguities of the digital screen as photographic and computational space intersect.
\end{abstract}

Keywords: photography, perspective, proprioception, anamorphosis, topology, digital aesthetics

In Elad Lassry's brief, nine-minute film Untitled (2008), four actors-three women and one man- 'play' with a blue-and-yellow trompe l'oeil house painted on a white backdrop. The figures manoeuvre awkwardly around the coloured lines and graphic edges of this bright, box-like structure. One woman stands just outside a doorway; another repeatedly tries, and fails, to rest her arm on the windowsill; the man strains to keep his body within the building's imaginary threshold; or, in a group portrait, they all sit together, their feet dangling off its illusory roof. The camera, instead of tracking their movements, remains stationary over the course of a dozen frontal, establishing shots. Stiffly holding their poses, the actors may falter in their respective positions, but the picture frame that encloses them, along

Sæther, S.Ø. and S.T. Bull (eds.), Screen Space Reconfigured. Amsterdam: Amsterdam University Press, 2020 DOI 10.5117/9789089649928_CHo6 
with the cartoonishly flat space that they inhabit, does not. This tension between the mobile figures and their conspicuously immobile ground creates a hallucinatory effect: we watch as the supposedly fixed contents of a seemingly static photograph subtly, almost imperceptibly, begin to shift and waver before our eyes.

Modeling Untitled after a series of photographs found in a 1971 science textbook, the Los Angeles-based Lassry (b. 1977) — best known for his own studio still-life photographs of uncanny objects and cleverly staged perceptual glitches - sets in motion a sequence of still images originally intended to illustrate the camera's ability to 'trick' the human eye. Yet Lassry reenacts this lesson in 'forced perspective' for quite a different purpose. By transferring the exercise to film, he is able to draw heightened attention to the presence of the human figure as a vital point of identification for how we, as viewers, often come to experience 'motion' as a powerful disorientation of our embodied sense of space in relation to the picture-and, in this case, the picture as a screen. For the actors in Lassry's film do not simply switch positions from one shot to the next, their bodies somehow appear to alter their dimensions during this surreally elongated play in perspective. They advance and retreat from foreground to background, top to bottom, wandering from left to right across the frame. At once tiny and gigantic, they shrink and stretch like living paper doll cutouts. Through their sudden changes in size and scale, the very space within the picture morphs into an uncertain construct. Where exactly is the solid ground upon which these oddly volatile figures — or the camera, or we ourselves — can be said to stand?

Starting here with Lassry — and returning later to delve further into the curious slippages in his work-in what follows I offer a detour through some other instructive perspective games and eye exercises in which the human body is deployed as a site of instability in order to challenge conventional notions about how photographic space operates naturalistically, for example, as a 'mirror' or 'window' onto the world. ${ }^{1}$ In interviews commenting on the optical tricks scattered throughout his practice, Lassry has insisted that his

1 The metaphor of the photograph as a 'mirror' or 'window' can be attributed to many sources, from the Albertian model of the picture as an 'open window' and Oliver Wendell Holmes' oft-cited description of the photograph as a 'mirror with a memory' in his 1859 text, 'The Stereoscope and the Stereograph' to curator John Szarkowski's influential 1978 show 'Mirrors and Windows: American Photography since 1960' at the Museum of Modern Art in New York, NY. Whether as an expression of the photographer's subjective choice of framing or as a record of a fleeting reality, the photograph in these accounts either reflexively bounces back or directly opens onto the spaces that it captures. Rendered rhetorically 'transparent' in this way, its surface is understood as something to 'see through'. 
photographs are not merely representations of the scene before the camera but, more polemically, 'tools that teach', facilitating a 'coming to terms with seeing.' ${ }^{2}$ Likewise, for the artist and educator László Moholy-Nagy (1895-1946) and the early $20^{\text {th }}$-century psychologist and ophthalmologist Adelbert Ames, Jr. (1880-1955) - the creator of the celebrated optical illusion of the Ames room - the camera as a machine of 'perfect' perspective and the photograph as the picture that it produces were not tools for replicating a preexisting vision of reality. ${ }^{3}$ Rather, they are re-tooled to guide viewers through the uniquely ambiguous space that emerges to our perception through the photograph: one that vacillates between the two-dimensional and the three-dimensional, flatness and depth. In his pioneering philosophy of a 'New Vision', Moholy-Nagy presciently expressed sentiments similar to Lassry's. He saw the photograph as an infinitely resourceful tool for pushing viewers to explore the visual and cognitive terrain of a new spatial logic. By traversing these hidden potentialities of photographic space, Moholy-Nagy believed that we might not just reach a 'coming to terms with seeing' but also learn to 'see the world with entirely different eyes'. ${ }^{4}$

This essay looks back towards Moholy-Nagy's call for a New Vision to consider what such a strong imperative to see anew means for us today. Our understanding of the limits and conditions of photographic space once again requires revision as the intensification of digital technology-and with it, the virtual layers and informational flows of the computer screen's dynamic interface-becomes the encroaching 'ground' for the medium's widespread mode of production and display. The present discussion will focus on the role of the human body-our own and those located within the picture-in negotiating these increasingly novel spatial possibilities. From Lassry's post-'Pictures Generation' work to the techno-utopian rhetoric of Moholy-Nagy's modernist photography to the life-sized illusion of the Ames room - these historically and aesthetically disparate case studies intersect in their common use of the body as a pivot point for proprioceptively

2 Lassry, 'Interview with Ryan Trecartin', pp. 140-144.

3 See Galassi, Before Photography, pp. 511-526. and Snyder, 'Picturing Vision', pp. 511-526. Galassi sums up photography as the 'epitome of realism' and its invention as 'nothing more than a means for automatically producing a picture in perfect perspective' (p. 512). In a critique of the medium as this 'tool of perfect perspective', Joel Snyder argues that we should not equate the realism facilitated by photography with the real itself: 'Cameras do not provide scientific corroboration of the schemata or rules invented by painters to make realistic pictures. On the contrary, cameras represent the incorporation of those schemata into a tool designed and built, with great difficulty and over a long period of time, to aid painters and draughtsmen in the production of certain kinds of pictures' (p. 511).

4 Moholy-Nagy, Painting, Photography, Film, p. 29. 
introducing viewers to the spatial paradoxes that can proliferate within the photograph. Examining the particular ways that bodies are organized within and by the picture, I uncover a genealogy of photographic space that is ambiguous and synthetic rather than self-evident or realist. The term 'proprioception' (from the Latin proprius, meaning 'one's own', and capere, 'to take' or 'to grasp') designates those internal faculties of our nervous systems that govern our awareness of the relative position, movement, and speed of our bodies in space. While proprioception does not only, or necessarily, depend on vision, I argue that we 'see the world with entirely different eyes' precisely through our proprioceptive adaptation to the unfamiliar topologies that the photograph can generate. The New Vision as a 'vision in motion' turns on this transformation of our seeing into a fully kinesthetic act. We discover new positions from which to see and, finally, reconceive of our place in the world through the bodily encounter with the unpredictable configurations of photographic space.

In a series of black-and-white photographs taken during the late 1920 s at the Bauhaus in Dessau, Germany, Moholy-Nagy orchestrated his own hideand-seek games of perspective meant to puzzle and disorient the viewer. Unlike Lassry's film, however, these games were staged on the real-life set of the iconic art school's stacked balconies and gridded glass facades. As with many of his peers in the post-WWI European avant-garde, Moholy-Nagy took advantage of the recent innovation of the portable, hand-held camera to document the accelerating sensory traffic of an industrial urban modernity. He ventured out with his lightweight Leica I to pursue unorthodox vantage points previously inaccessible to the large-format, baseboard camera with its bulky equipment and constrictive movements that had characterized the medium's earlier decades. Exercising a physical boldness that matched the camera eye's newfound mobility, Moholy-Nagy sought to capture 'the view from below, from above, the oblique view'. Caught in mid-air looking up or down from unprecedented angles, the contortions of such views, he declared, would 'often disconcert viewers who take them to be accidental shots'. 5

The one or two human subjects present in these off-kilter snapshots are no more stably situated. Mimicking the stance of the photographer, they either glance down from a great height or glimpse upward from below. Peeking and peering at each other and at Moholy-Nagy, they interact with the blocky modernist structures around them like adventurous children climbing an enormous architectural jungle gym. In one image, a lone man, 


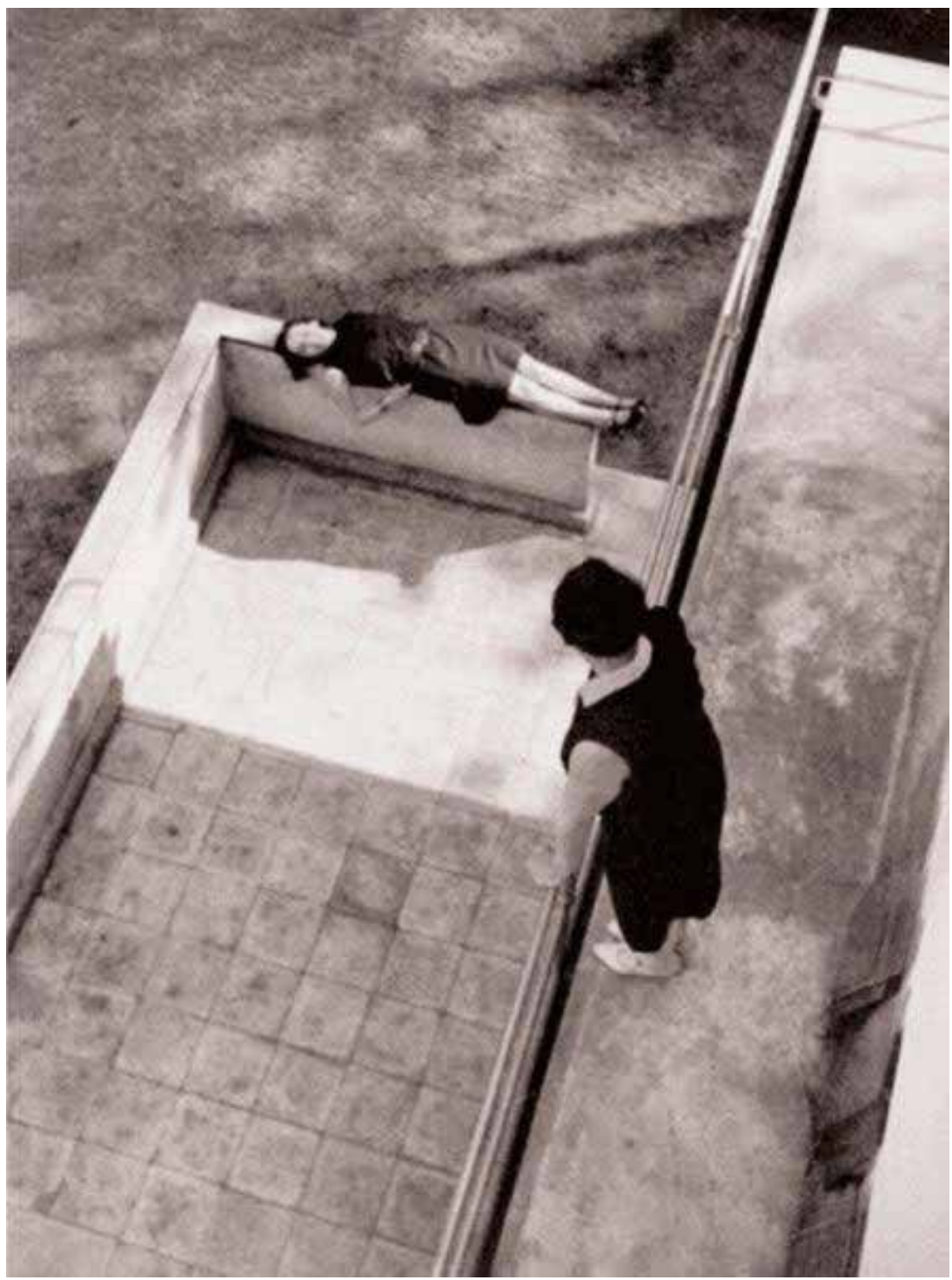

10. László Moholy-Nagy, Untitled, c. 1926-8.

installed on a precarious pinnacle, throws an arm and a leg over the corner of a railing as if he is about to jump or fly off. Moholy-Nagy dramatically skews his camera from the ground up so that the man is balanced at the apex of what appear to be tiers of steel and cement soaring into the sky. In yet another image, two women are positioned on separate floors of a Dessau master-house. One lies on the ledge of a lower terrace as she looks up at a second woman leaning over an upper balcony with her back turned 
to Moholy-Nagy who, somewhere still higher up, completes this zigzag of staggered bodies and gazes. In these photographs largely composed of shadowy planes and slashing diagonals, the human figures anchor our sense of scale and distance. But their irregular placement in the space of the picture-tilted this way and that, with their partially obscured bodies never facing forward nor securely settled on a horizontal-vertical axis-elicits a momentary vertigo. We, too, must struggle to get our bearings as we figure out where to align our point of view.

For contemporary viewers, Moholy-Nagy's photographs likely seem quaint, so recognizable by now are the modernist tropes of defamiliarization, abstraction, and the fragmentation of perspective into multiple, simultaneous points of view. Indeed, throughout his prolific writings - collected in his three books Painting, Photography, Film (1925), The New Vision (1938), and the posthumous Vision in Motion (1947) - Moholy-Nagy enthusiastically embraced the influence of Cubism, Constructivism, Futurism, and other artistic movements of the time. Inspired by their vanguard formal strategies, he developed his programme for a New Vision, a term he coined to encompass his experiments in sculpture, theatrical design, lens-less photograms and photo-collage, in addition to his camera-based photography. Moholy-Nagy's objective was to usher in a 'new viewpoint in the visual arts [that] is a natural consequence of this age of speed which has to consider the moving eye. ${ }^{6}$ Modern viewers, he wrote, see 'persons and things in quick succession, in permanent motion'? The ambition of the New Vision was to galvanize viewers towards an 'ocular gymnastics' aimed at reconditioning 'our optical organ of perception, the eye, and our centre of perception, the brain., ${ }^{8}$ Much like the acrobatic arrangement of human figures in his photographs, this cultivation of a 'moving eye' did not rely on the literal mobility of the image but rather, in a radical disruption of the prevailing optic, on prompting viewers to see the space inside of the picture differently.

In this respect, the renewal of vision advanced by Moholy-Nagy was as much about unlearning certain ways of seeing as it was about inciting new ones. The first task was to dismantle the paradigm of one-point, linear perspective inherited from the tradition of Renaissance painting. Moholy-Nagy claimed that this outdated model of picture-making and looking had been indelibly 'stamped upon our vision'. ${ }^{9}$ The invention of the camera in the $19^{\text {th }}$ 
century, moreover, with its synthesis of the principles of linear perspective and the camera obscura, only strengthened its imprint on our habits of seeing. But, as Erwin Panofsky reminds us in his landmark Perspective as Symbolic Form, it is important to remember that the artificial viewpoint created by linear perspective is in no way the 'mirror' for our seeing that it is popularly thought to be. As a mathematical formula for rationalizing space, it is a calculated distortion of our sight as well as our sense of space. Hubert Damisch elaborates on this point by tracing the origins of perspective to a technique of architectural draftsmanship, chiefly devised to establish the illusion of three-dimensional depth on a two-dimensional surface. Famously applying these rules to painting, Leon Battista Alberti instituted perspective as the underlying backdrop for the genre of story painting or istoria. The basic geometry of perspective-with its reticular grid of parallel lines converging at a single vanishing point on the horizon-became the standard method for holding down the field of representation in support of a naturalistic realism. ${ }^{10}$ It is this conception of pictorial space as a 'setting for sentimental naturalism" ${ }^{\prime \prime}$ — canonized by painting and reinforced by photography — that Moholy-Nagy so vehemently opposed.

Seen in this light, the deliberate dynamism of Moholy-Nagy's pictures attempted to counteract the longstanding codes of linear perspective. And yet, from an architectural to a painterly frame-and, as I will address, a photographic one-perspective itself takes on a decisively body-centreed emphasis. Besides generating the illusion of depth, it is primarily employed as an indispensable if invisible staging device. For Alberti, it was mainly a preliminary exercise to prepare the ground for sketching out the size, proportion, and distance between human figures in space. Remarking on the desirable features of the istoria, for instance, he encouraged painters above all to master the 'movement of change of place' within a picture, so that 'some bodies are placed towards us, others away from us [...] some drawn back, others high and others low'. ${ }^{12}$ This meticulous choreography of bodies in varying states of gesture and motion necessitated perspective's systematic organization of pictorial space, mapping out a gridded guideline for their arrangement. With its assimilation into painting, which, as Damisch observes, was 'less interested in space itself than the bodies it contained', perspective was

10 See Panofsky, Perspective as Symbolic Form; Damisch, The Origin of Perspective; Alberti, On Painting.

11 Moholy-Nagy, Vision in Motion, p. 273.

12

Alberti, On Painting, p. 79. 
thus formalized into an index of bodily orientation, 'equivalent to a network of spatial adverbs' indicating 'what is here, what there, and what over there'. ${ }^{13}$ The measured distribution of bodies within this highly theatricalized scheme effectively converted the fictional space of the picture into a hypothetical extension of our own.

At this juncture I hope it is apparent why the disarrangement of bodies within Moholy-Nagy's photographs is significant. Neither he nor his subjects are ever in their 'proper' place according to the realist dictates of linear perspective, which strictly delimits the movement permitted within its geometrical bounds. For beyond putting bodies into place within the picture, the positions of bodies outside of it-namely, our bodies as viewers - are inextricable from the complex network of spatial orientation that perspective lays out. In her book The Virtual Window: From Alberti to Microsoft, Anne Friedberg elegantly summarizes how the viewer stands at the crux of the intricately imagined scenes of central perspective. She cites Alberti's instructions to place the vanishing point of a painting to coincide with the height of a universalized viewer, such that 'both the beholder and the painted things he sees will appear to be on the same plane'. 'In this way', Friedberg explains, 'the body of the viewer suggests a scale for the bodies in the representational confines of the painting. The human was in a central position as a spectator in front of a pictorial world but was also the measure of the world. ${ }^{14}$ This viewer is furthermore required to stay immobile for the perspectival illusion to be convincing. Leveling our inherently mobile and binocular way of seeing - with two eyes in a head on a moving body-perspective unilaterally reduces our vision, and the world, to the monocular 'peephole' of the vanishing point.

With his plan for a New Vision, Moholy-Nagy enlisted his body and the camera to dislodge viewers from this unmoving centre. Looking up, looking down, from side to side, he defied the camera's automatically 'correct' perspective, inserting crisscrossing horizon lines and erratic vanishing points. The displacement of human figures in his photographs - one farther, one closer, one above, one below - provides another cue to recalculate our bearings. We are not on the same plane as these figures and, like them, we are mobile. It is in this vein that Moholy-Nagy links the body to vision through the category of motion. Explicitly defining space through the body, he states that 'space is the relation between the position of bodies', and 
'spatial creation is the creation of relationships [between the] position of bodies'. Privileging vision in this creation of new spaces, he goes on:

Each of our senses which can record the position of bodies allows a grasping of space. Thus space is known to man, first of all by means of his sense of vision. This experience of the visible relations of positions of bodies may be checked by movement-alteration of position [...]. From the point of view of the subject, space is naturally to be experienced most directly by movement. ${ }^{15}$

Without naming it as such, Moholy-Nagy describes a proprioceptive process of 'seeing' space through bodily movement. While our vision can orient us in space, it is our bodies that come to know that space by moving through it. By registering the incremental displacements of our bodies, our vision helps to control the reactions of our muscles and joints in propelling our locomotion through the world. New spaces are created by and within the picture when we find ourselves trying to move through — here cognitively rather than somatically—positions of seeing that we had not known before.

The goal of the New Vision to 'see the world with entirely differently eyes' is therefore deeply connected to this continual repositioning of our bodies in response to the picture's cognitive pull as a point of spatial orientation. Linear perspective acts like a compass that points our vision, and our bodies, in one direction. By contrast, Moholy-Nagy remakes the space of his pictures into a playground for setting our 'vision in motion' through an intensive 'gymnastics' of the eye and brain. He draws new visual and spatial lines for the viewer to follow. Yet, in his use of the camera and the photograph to 'activate' our vision, we arrive at a crossroads where painting and photography diverge. Where the positions of bodies in a painting belong to the sole discretion and skill of the artist, this is not true of the camera, with its 'objective' capacity to record an indexical image of the world. ${ }^{16}$ How does

15 Moholy-Nagy, The New Vision, p. 163. Besides sight, the other senses that Moholy-Nagy lists are a 'sense of hearing', a 'sense of equilibrium', and a 'sense of locomotion'. These three senses all fall under the heading of the vestibular system, which refers to the organs in the inner ear that regulate spatial orientation, balance, and acceleration with respect to gravity and movement. In conjunction with a sense of vision, the vestibular apparatus contributes to our overall muscle-joint sense of proprioception, although here I concentrate on the visual aspect. 16 While I have bracketed a discussion of the medium's indexicality in this essay, along with the spatial metaphors of a 'mirror' or 'window', the photograph has also been compared to a 'pencil of nature' (William Henry Fox Talbot), a trace of 'that-has-been' (Roland Barthes), or 
perspective as an instrument of bodily orientation 'stage' space within the photograph? What happens to the function of perspective, and the body in perspective, in the passage between these two mediums? Damisch presents a possible answer to these questions when he posits that perspective was first 'an extension of architecture', second 'an extension of theatre', and third 'an extension of "decoration". ${ }^{17}$ Perspective most clearly adopts this last guise when confronted with the real bodies and spaces before the camera. It recedes into something more like a prop, a movable article of scenery or décor. In the transition to the photograph, I contend that a distinctly ambiguous space — available to many grounds of orientation— gradually becomes detectable to the viewer.

The well-known phenomenon of the Ames room demonstrates how the peculiar ambiguity of perspective within the photograph can trouble our proprioceptive ability to locate and position ourselves in the world. The unusual behaviour of human bodies upon entering the room exposes the structural breakdown of perspective when it is utilized as an ornament of illusion instead of as a tool of realism. The room was designed in 1934 by Adelbert Ames, Jr., a polymath who invented several ingenious games of perspective. In a version of the room seen here, two women wearing complementary floral-print dresses look directly at the camera. The woman on the right appears twice as large as the woman on the left. The smaller woman casts appropriately diminutive shadows on the massive walls behind her, just as her companion casts appropriately gigantic ones against those same walls that can barely accommodate her. The low ceiling bears down on the woman on the right, whose body is turned in profile towards the woman on the left, herself turned at an angle towards the viewer. Thickly outlined on the room's walls are identical 'windows' that

a 'death mask' for time (André Bazin). Following a concept borrowed from the semiotician Charles Sanders Peirce, the photograph has been widely theorized as an 'index', or a sign with an existential connection to whatever it represents. Light 'touches' and binds the subject photographed to a chemical base, transforming this ephemeral link into a material fact. The shift from analog to digital technology has been posed by critics and scholars in terms of an ontological loss of the photograph's indexicality, since the digital camera translates light into numerical code. For a challenge to this position, see Tom Gunning's 'What's the Point of an Index? Or Faking Photographs', pp. 23-40. Gunning disentangles the 'truth claim' of the photograph from its indexical status, arguing that even before the arrival of the digital, the photograph as a document or 'proof' of the real was highly manipulable and mediated. Gunning asserts that the digital does not eliminate the photograph's indexicality, it simply stores it differently. What the digital arguably effects more is the photograph's iconicity, or the relation of resemblance between the picture and what it depicts.

17 Damisch, The Origin of Perspective, p. 237. 


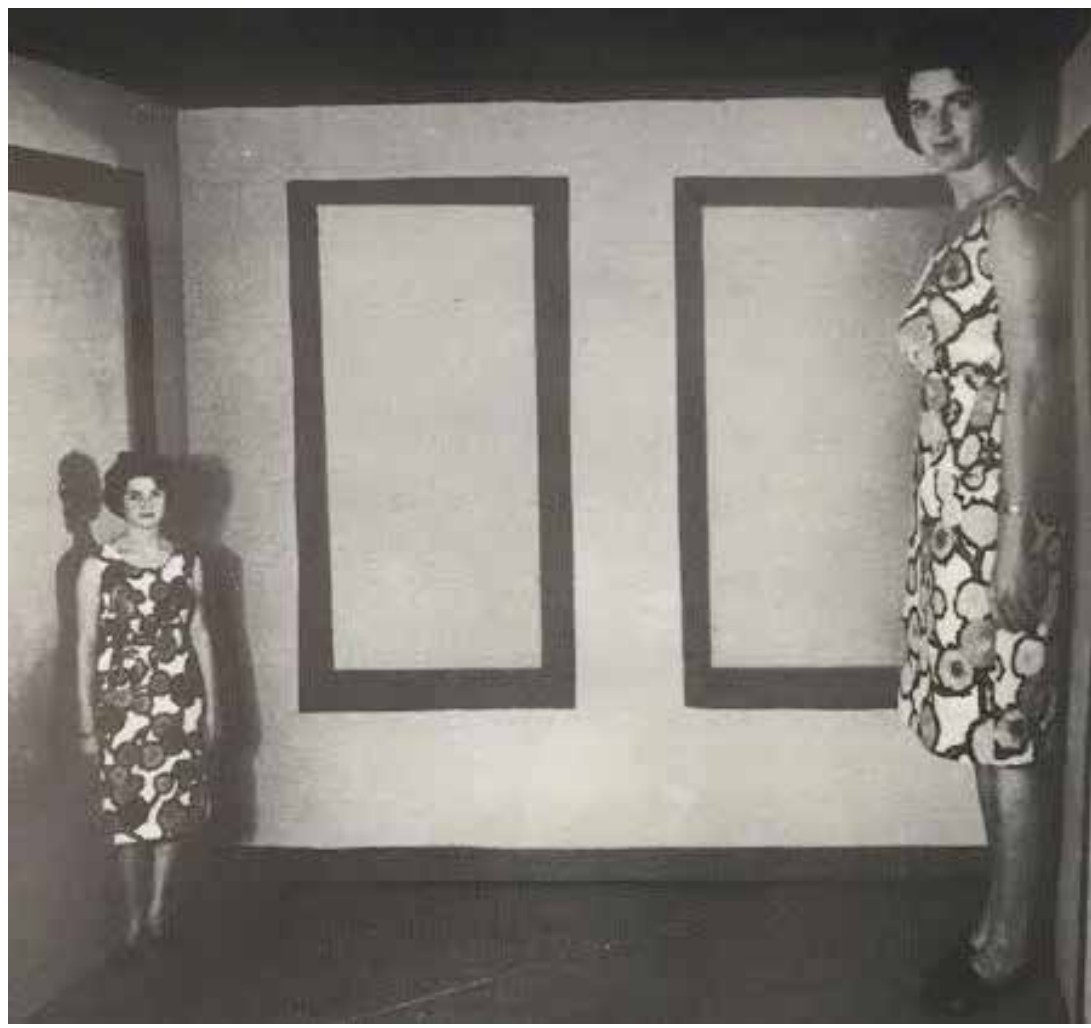

11. Illustration of 'The Ames room' from Richard L. Gregory, Eye and Brain: The Psychology of Seeing, 1966.

accentuate the pair's difference in size. If we were to envision the room empty, or even with one woman, it would be relatively unremarkable. But because it contains two women, so drastically disproportionate in scale, we are left to wonder how our own bodies might fit into this perplexing funhouse of a room.

A closer inspection yields a clue to the room's anomalous construction. The women are in fact at a diagonal from each other. The 'shorter' woman is positioned at the back left corner while the 'taller' woman has been pushed to the front right edge. They nonetheless appear to be on the same plane. The floor is flat, the walls are straight, and they stand calmly and vertically upright. How, then, are they taking up space in this incongruous fashion? Is it the bodies, the room, or our eyes that are deceiving us? In his classic text Eye and Brain: The Psychology of Seeing, Richard L. Gregory clarifies this conundrum as a misapplication of our 'common sense' experience of rooms: 'Evidently we are so used to rectangular rooms, we accept it as axiomatic 
that it is the objects inside (the people) which are odd sizes, rather than the room being an odd shape'..$^{18}$ To the contrary, the Ames room is assembled as an unevenly distorted trapezoid. The floor recedes downwards to the left to form a backwardly canted stage. The width and height of the 'windows' narrow from left to right. The interior horizon line slopes back at an incline, sliding the vanishing point from the centre to the lower left side of the room. Like Moholy-Nagy's photograph, the women are on separate planes and at different distances from us. The smaller woman, who is farther away, is slightly below our line of sight, and the bigger woman, who is nearer to us, is slightly above it. Stationed at an aperture for one eye, the viewer stands outside looking in. We become proxies for the camera eye, flattening three-dimensional space into the illusion of two.

The Ames room reveals how startling things can become when the restrictions of linear perspective, embedded into the very mechanics of the camera, are projected onto bodies and spaces that exceed its prescribed view. This is the 'blind spot' of perspective that Ames manipulates through the technique of anamorphosis, which bends and plays with the constraints of perspective. An anamorphic picture - from the Greek ana-, meaning 'up' or 'back', and morphe-, 'to shape'-looks distorted when seen frontally but rights itself from a sideways view. The trick of the Ames room lies in its anamorphic distortion of the physical space before the camera, expanding and contracting the coordinates of a 'normal' rectangular room to fabricate an impossible reality right before our eyes. Perspective stops acting as a single point of orientation and transforms into a decorative prop that can be shifted around to stage unlikely spatial arrangements. Through this vivid illustration, the photograph unveils itself as neither a perfectly mimetic reproduction of the space in front of the camera, nor as a totally distorted view of the world that cannot be trusted. Between these two extremes, it produces a spatially ambiguous reality that fluctuates somewhere between two-dimensional flatness and three-dimensional depth. In the interstices, I argue, there arises a kind of space that we could not see, and would not even exist, without the photograph.

For Moholy-Nagy as for Ames, the pedagogical and aesthetic value of this in-between space-not fully bound nor unbound from the grounding grid of linear perspective-is what makes the photograph into an exceptionally versatile tool for mobilizing our vision in new directions. By positioning the human figure as a strategic site of instability in their pictures, they affirm that our perception of space, whether pictorial or physical, is tethered to 
our embodied knowledge of 'what is here, what there, and what over there' in the ongoing proprioceptive readjustment of our bodies toward other bodies and objects in the world. Ames's use of anamorphosis to carry out this perceptual exercise highlights Jonathan Crary's assertion in Techniques of the Observer: On Vision and Modernity in the Nineteenth Century that 'the veracity of the camera', despite its discursive status as an impartial 'eye-witness', has always been 'haunted by its proximity to techniques of conjuration and illusion.' ${ }^{19}$ Crary persuasively shows that the vagaries of visual illusion were historically harnessed as a heuristic process - through proto-cinematic devices such as the thaumatrope, the phenakistiscope, the zoetrope, etc.- to 'train' viewers to become conscious of the inescapable corporeality and, consequently, imperfection, of our visual engagement with the world. The illusion of motion that these optical toys induced was attributed to flaws and idiosyncrasies in the physiology of the human eye. Splitting perception from the object perceived, everything we see is filtered through, in Crary's words, 'a body with an innate capacity, one might even say a transcendental faculty, to misperceive - an eye that renders difference equivalent'. ${ }^{20}$

Crary's identification of the unreliable nature of our seeing is especially relevant here because, like our bodies, our eyes and minds are in constant motion. I would counter, though, that where the photograph ostensibly 'fixes' a stable view of the world, this view has an equally inconstant nature built into it. The illusions that spring from the photograph's ambiguous space-like the Ames room's abnormal scaling of the human body-are the byproducts of our failure to conceive of the full range of spatial configurations concealed within the picture. On this discrepancy, Ernst Gombrich astutely notes that the intrinsic geometry of linear perspective suppresses this 'infinite number of related configurations', 'just as not one but an infinite number of related objects would cast the same shadow if placed in the beam emanating from a one-point source'. Looking at the picture, we know, in other words, that the vanishing point structure of perspective can create space where there is none, simulating distance via the measured diminution of bodies by position and size. But we cannot easily invert this structure, translating it back into the amorphous flux of reality, without falling into a frequent perceptual trap. As Gombrich elucidates, while a picture in perspective can signify a 'class of objects', these are not objects that 'would ever be known in our environment'. We routinely mistake 'one specimen 
of the class - the flat design on the plane in front of us - for another, the solid object over there'. ${ }^{21}$ Following Crary, our eyes render 'equivalent' the difference between a picture of an object and the object itself. Even though we tend to 'see through' the surface of the photograph, this does not mean we can successfully extract a three-dimensional world from a two-dimensional representation. Misperceiving the 'relation between the position of bodies' in the Ames room, we stumble across a space inside of the photograph that is far more enigmatic — and ultimately indeterminable - than what it looks like from the outside.

What are some of the properties of this strange space inside of the photograph? Extending Gombrich's idea that any perspectivally constructed picture harbors within it an 'infinite number of related configurations', I propose that we think of the photograph not as a two-dimensional representation of a three-dimensional world - a topography of surfaces-but as a topology. Topology is a field of mathematics that studies geometric objects that can be continuously transformed without losing their originary qualities. Topologically speaking, a circle is equivalent, or 'homeomorphic', to a square. The points and lines of either can be pulled or smoothed to map one onto the other. A wheel or a torus, on the other hand, which includes a hole, is not equivalent to a circle. From the point-coordinate system of a Euclidean metric space to the more elastic, point-'neighbourhood' system of a topological space, the manner by which a torus and a circle undergo changes in distance and closeness, connectedness and compactness, is essentially different. ${ }^{22}$ I present these elementary examples here-although the nuances of a topological analysis of forms is beyond the scope of this essay - to suggest that we might approach the photograph as one such topologically malleable space. Every photograph made with a camera is a two-dimensional plane mapped by the grid of linear perspective; wherever the camera is positioned, or whatever is in front of it, each picture consists of a concrete point of view and a projected vanishing point. In the protean space between those two points, however, there exists an open set of related possibilities. The 'shape' of the photograph can be thought of as this topology of variable configurations - either found in the world, like Moholy-Nagy's 'accidental shots', or staged for the camera, like the Ames room. An infinite number of homeomorphic distortions and deformations can occur to the

21 Gombrich, The Image and the Eye, p. 191.

22 See Bert Mendelson, Introduction to Topology. For a concise and accessible explanation of terms, see the prefaces to Chapter 2 on 'Metric Spaces' and Chapter 3 on 'Topological Spaces'; and Jeffrey R. Weeks, The Shape of Space. 
space inside of the photograph within the parameters of those two defining points. If the geometry of linear perspective rivets our vision to a flatly homogenous space, topology loosens up our qualitative experience of this space, twisting and turning viewers around a moving centre.

Reframing the photograph as this generator of ambiguous topologies affords us more room, so to speak, in relation to it. When looking at the photograph, we can proprioceptively adapt ourselves to spatial arrangements that deviate from the typical, one-point perspective. This bodily 'seeing' can help us to imagine and materialize other ways of taking up space in the world that do not correspond to the inflexible position assigned to us by perspective. Perspective, as already mentioned, is a monocular depth cue implanted within the picture. It should not be confused with how we perceive depth, which is a function of how our eyes and minds integrate an incessant stream of visual information to stabilize a 'constant' picture of the shifting reality around us. This scaling for perceptual constancy guarantees, among other things, that we know that bodies stay a uniform size, even as they appear bigger as they come nearer or smaller from farther away. We labour ceaselessly, if unconsciously, to estimate the distance between people and things as they, and we, move around in space. But these same calculations cannot be applied to the people and things we see in a photograph. In our assessment of the Ames room, we overlook the fact that perspective in the picture 'sets constancy scaling directly. ${ }^{23} \mathrm{We}$ miscalculate the distance between the position of our bodies at the viewing point and the position of the bodies arrayed around a displaced vanishing point. Illuminating the fundamental inconstancy of our vision, the optical illusion of the Ames room generates an unforeseen topological space, one that needs to be navigated differently than the preset mental template of linear perspective, which falsely imposes the illusion of a coextensive space shared by the bodies within the picture and without.

I submit that in coming to 'see' these mutable topologies nested inside the photograph, the epistemological force of illusion has a crucial cognitive effect. Gregory's insights remain a key reference on this topic of optical illusions. He maintains that in looking at two-dimensional images, there are two kinds of scaling to account for: "upwards" from depth cues and "downwards" from seen depth'. ${ }^{24}$ We synthesize 'upwards' from visual signals to our eyes, and 'downwards' from our store of perceptual knowledge. Conflicting cues within the picture can cause us to mismatch what we know onto what we 
see, engendering the cognitive 'slips' of illusion. Gregory formulates this 'bottom-up' and 'top-down' model to rectify these perceptual errors. I borrow his more 'active' understanding of perception to update Moholy-Nagy's New Vision for the digital era. The ambiguities of photographic space are becoming more and more perceptible in the crossover to the digital screen. Illusions run rife in this overlap as one medium blends into the other. Lassry's eye exercises carefully exploit the widening gap between what we see and what we know to stimulate viewers to look up and look down, stretching old pictures into a new digital shape.

When speaking about his work, Lassry — who, besides photography and film, has done dance performances and sculptural installations - consistently refers to his interest in what he calls 'nervous pictures'. 'A nervous picture', he says, 'is one that makes your faculties fail, when your comfort about having visual information, or about knowing the world, is somehow shaken.'. ${ }^{25}$ Making the bulk of his work in his East Hollywood studio, Lassry has been associated with artists like Walead Beshty, Roe Etheridge, Annette Kelm, and Eileen Quinlan, who in the last decade have been formative in revitalizing the field of contemporary art photography. In the wake of the 'Pictures Generation' legacy of the late 1970s, these artists interrogate the photograph as both a conceptual object and a heavily circulated cultural commodity. In particular, Lassry's geographic propinquity to the movie industry has supplied him with a readymade archive for appropriation: a paper trail of stock and celebrity photos, movie stills, vintage Life magazines, and the like, which he richly mines. Explaining his attraction to the anachronistic charge of these mass media artifacts, he relates: 'I'm fascinated by the collapse of histories, and the confusion that results when there is something slightly wrong in a photograph'. ${ }^{26}$

To see Lassry's work in person, hung on the walls of a gallery or museum, is to be presented with images that invite us to play that familiar game of 'What is wrong with this picture?' Lassry's photographs are generally printed at the size of an eleven-by-fourteen-inch magazine page. Lacquered frames echo the saturated colour scheme within the photograph, turning the two-dimensional picture into a self-contained, three-dimensional object. When it was first shown at the Whitney Museum of American Art in 2009, Lassry's film Untitled, with which I began this chapter, departed somewhat from this exhibition format. It was screened in the 'black box' of a darkened room, with viewers free to walk about the whirring $16 \mathrm{~mm}$ projector or to get 


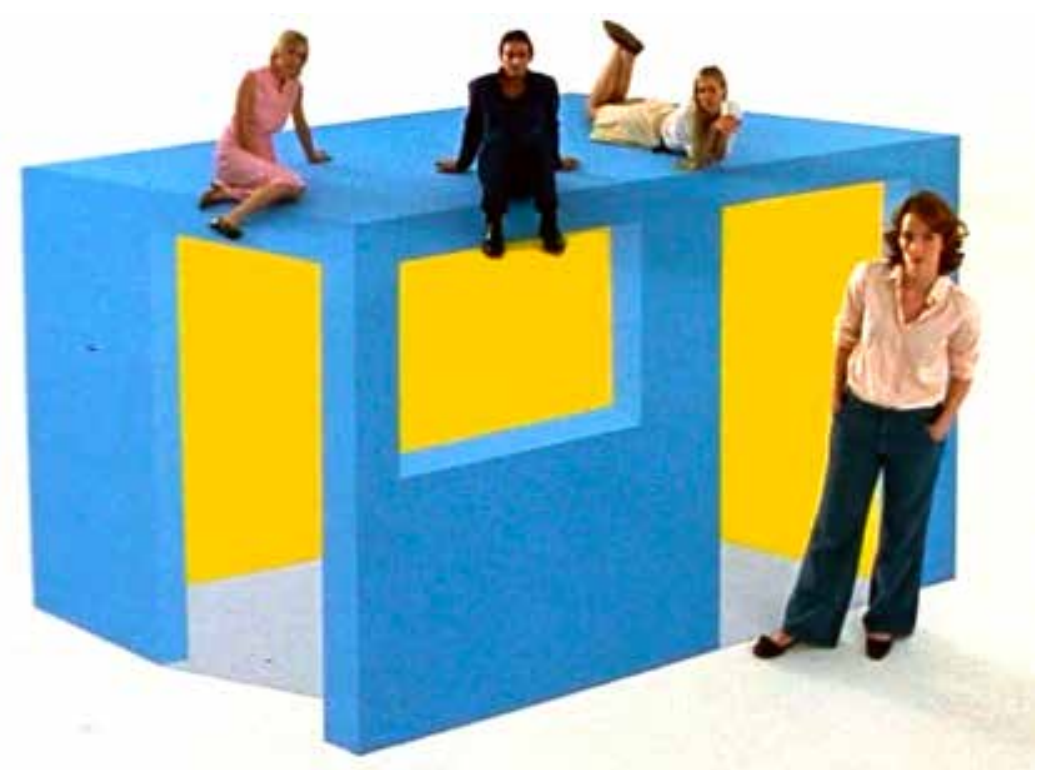

12. Elad Lassry (b. 1977), still from Untitled, 2008. 16mm film, colour, silent, 9:20 min. @ Elad Lassry, courtesy of 303 Gallery, New York.

as close as possible to the projected image. This physical mobility was not in itself what made the experience exceptional; it was the human figures inside of the picture, who, fidgeting and shifting, overtly solicited us, as if we were indeed occupying the same room. In the photographs from which Lassry drew the mise-en-scène for the film, the actors alternated between the 'right' and 'wrong' positions to educate students about the placement of the camera to produce a picture in accurate perspective. Subverting this premise, Lassry lingers on the flickering disjunction between these two positions - one where the illusion of three-dimensional space clicks in and the other where the actors are stranded in a two-dimensional 'flatland' - to provoke a 'nervous' reaction from viewers. We sympathetically recalibrate various parts of our bodies to make the illusion 'work', mirroring the bodies in the film that cannot seem to keep still.

In one episode, the woman in a pink dress poses her arm over the house's window. Her body droops and drapes, hovering just a bit above or below the mark. She looks up at the camera, which seems to be perched somewhere above her, with her feet planted on a noticeable downslope. In the film's most comically jarring shot, three of the actors, each of proportionally equal size, lounge on the roof, while the fourth, now twice as big as her companions, fills the height of the house's doorway. We know from the lesson of the Ames 
room that the space in front of the camera must be distorted, and that the camera itself-along with our point view—is probably floating on some other plane. Where 'up' equals farther back and 'down' farther forward, we might guess, among any number of configurations, that the foreground of the picture is tilted downwards, the background tilted upwards, and the entire ground, perhaps, tipped sideways. The weird anti-gravity of the painted backdrop cancels out all depth of field, conflating the near and the far. We quickly realize, in our scaling 'upwards' and 'downwards' for constancy, that the space the actors see cannot possibly correlate to the one we see. As the perspectival illusion of the house fades into the two-dimensional prop that it is, we get the weightless feeling, as Fredric Jameson has written in a different context, of a 'space existing in two distinct dimensions at once, in one of which it leads a rectangular existence, while in that other simultaneous and unrelated world it is a parallelogram'. ${ }^{27}$

Staging a still photograph as a moving image, Lassry teaches us how to look at the photograph as a covertly kinetic space, even if it emphatically does not move. Like Moholy-Nagy and Ames, he interposes the human body as a site of instability to convey the aberrant topologies that can propagate within photographic space. Tracing out the 'relations between the position of bodies' from shot to shot, we start to discern that the space inside of the photograph can collapse manifold, sometimes incompatible planes of orientation into one. Lassry has said that, as a formal tactic, he likes to toy with the camera's propensity to distort space and flatten dimensionality. Where an ordinary photograph might have one plane in focus-the foreground, the background, or a subject centred in the middle ground-he prefers to have several subjects in focus, without a centre, leaving viewers to sort out these spatial contradictions on our own. ${ }^{28}$ Like the four figures in Untitled, bodies and objects in Lassry's pictures are regularly suspended in this liminal space of unresolved dimensions. In this regard, putting his work into dialogue with Jameson is apposite. The stylized nostalgia of Lassry's aesthetic undoubtedly resonates with the tenets of postmodern pastiche. But it is Jameson's description of a 'new kind of flatness or depthlessness, a new kind of superficiality in the most literal sense' that distinguishes what he names postmodern 'hyperspace' upon which I would like to dwell. ${ }^{29}$

Writing in the early 1980s, Jameson diagnoses this by now retro-sounding formulation of postmodern hyperspace as a symptom of the burgeoning 
digital or information age. Usurping the 'depth model' of an older, modernist space, this new space thrives on the 'hallucinatory exhilaration' of multiplying surfaces. In a memorable section of his essay 'Postmodernism, Or, The Cultural Logic of Late Capitalism', Jameson guides readers through the interior of the Westin Bonaventure Hotel in downtown Los Angeles, using it as an allegory for the physical experience of this hyperspace. The Bonaventure is portrayed as something like an impossible space: its mirrored, cylindrical outer shell, unmarked entryways, and meaninglessly colour-coded elevator towers (green, blue, red, yellow) spit visitors out into the 'placeless dissociation' and 'milling confusion' of indoor garden lobbies and pod-like gym balconies. Jameson extrapolates from this exasperating architectural folly to proclaim the utter bafflement of our bodies: "This latest mutation in space has finally succeeded in transcending the capacities of the individual human body to locate itself, to organize its immediate surroundings perceptually, and cognitively to map its position in a mappable external world. $3^{30}$ The 'compass' of linear perspective, with its orderly plotting of up and down, left and right, front and back, proves to be a thoroughly inadequate means of orientation within this supremely warped hyperspace.

For Jameson, the convolutions of postmodern hyperspace reflect the sprawling global network of late capitalism. Yet, like Moholy-Nagy, he isolates the human body as a visual and cognitive training ground. He issues his own injunction 'to grow new organs, to expand our sensorium and our body to some new, yet unimaginable, perhaps ultimately impossible, dimensions' ${ }^{31}$ Across a modernist and postmodern conceptualization of space, it is thus our bodies that are relentlessly impelled to speed up and rescale to spaces that are ever more pliable and beyond our grasp. Intervening in this race to upgrade the body, however, I put forth the speculative claim that the 'depthlessness' and 'superficiality' of Jameson's hyperspace, understood in the terms of the current cultural moment, are nothing but shorthand for the profoundly synthetic space of the digital screen. I use 'synthetic' in the dual sense of something manufactured as well as a bringing together, a synthesizing, of heterogeneous spaces. In the alternative genealogy of photographic space that I have delineated, the ambiguous topologies of the photograph prefigure the dislocations of postmodern hyperspace, which culminate in the infinite plasticity of the digital screen as an informationally driven and spatially changeable interface. While the computer screen defaults as a perspectival display, it can just as effortlessly morph into a topological 
space, with no predetermined centre. At its core, the computational space of the screen breeds what I would label as a rampant digital illusionism. Where the illusion of perspective in a photograph is inevitably tied to one position in space - and one ground upon which to position the body of the viewer - the screen can algorithmically remove and replace this ground, multiplying the illusory effects of perspective freed from the camera's rigid point of view.

The ascendance of this digital illusionism itself runs parallel to a genealogy of the computer as an information-processing system that subsumes, but exponentially surpasses, the optical logistics of linear perspective. In Software Takes Command, Lev Manovich aptly classifies the computer as a 'simulation-augmentation machine'..$^{2}$ As he points out, Photoshop applications like the paintbrush, eraser, clone stamp, drop shadow, or 'dodge', 'burn', and 'blur' filters replicate the effects of physical tools and phenomena in the virtual 'darkroom' or 'canvas' of the digital screen. Manovich cautions, though, that 'what begins as a reference to a physical world outside of the computer if we use default settings can turn into something totally alien with a change in the value of a single parameter'. ${ }^{33}$ Spanning the spectrum from simulation to augmentation, every photograph 'developed' through Photoshop can accumulate multiple layers' with infinitesimally adjustable degrees of transparency and opacity. Beyond the cut-and-paste of old-fashioned collage, the programme compresses these layers into a seamless composite. Within this multi-layered depthlessness, the 'prop' of perspective may be prominently displayed, occluded, or pushed to the side. The illusionism of the digital screen builds momentum from this accretion of perspectival positions and relations. The digitized image may initially look like a photograph-offering one view of the world from a pre-given position - but it can steadily mutate into something else. Again, the photograph does not move, but everything within it can be moved, placed side by side, or on top of each other. Two dimensions not only become three but four, or ten, or a hundred - a polyground of elements stacked in a paratactic, rather than a hierarchical, order.

And yet, as we saw with the Ames room, non-digital images and spaces can have palpably digital effects. They can look just as flattened, layered, deformed, and so on, confounding our sense of scale and direction, while deriving from a purely analog source. Lassry cannily situates his 'nervous pictures' on this digital-analog mimicry divide. Making analog photographs 
that look analog but that are discreetly modified by digital tools imitating analog tools, he instills the photograph with an elusive digital 'noise'. 'I [do] not feel it [is] necessary', he qualifies, 'for my photographs to look like what we think of as a digital photograph' ${ }^{34}$ But most of his photographs are nevertheless digitally enhanced or tweaked, folding algorithmic patterns into their analog grain. Two of his photographic portraits, Man 071 (2007) and Felicia (2008), trigger the dissonant effect of this digital illusionism. To make them, Lassry took multiple exposures with a large-format, four-byfive camera, which he then scanned and combined in Photoshop. Man 071 reworks the industry staple of a smiling actor's headshot into a perceptual problem. A smiling, shirtless man is photographed against a shallow blue backdrop with an accompanying blue frame. His face, neck, and shoulders are brightly lit, in focus, and still—all except for his eyes, which appear to pop out at us. The man stares off into the distance, but the vaguely $3_{3} \mathrm{D}$ blur, even dizziness, we come up against in trying to 'catch' his gaze unravels into a kind of 'autoscopy': we feel our own eyes trying to focus, to attain a sense of perspective.

Coming face to face with Lassry's photographs precipitates this fidgeting bodily nervousness. We hesitate: is the photograph moving or are we? In Felicia, Lassry amplifies this mesmerizing visual stutter. A young woman poses against a florescent frenzy of confetti dots. She smiles shyly at the camera with a sidelong glance, such that, as we move, her eyes seem to follow us. Felicia, more than Man 071 , appears to tremor. Recalling the vibrating shimmer of a lenticular print, it reverberates with a subliminal visual tinnitus, or a magnified motion parallax. The outer field of our peripheral vision overtakes the dominant focus of our central vision as the invasive blur that permeates the picture distracts us from fixing on any one point of view. Akira Lippit has eloquently written that in Lassry's photographs, 'nothing appears to move, yet the feeling of movement persists everywhere within the image'. In the 'motionless stir of the image', one sees 'the act of another looking, the movement of another's look'.35 The micro-actions of our seeing are doubled and projected back at us. The photograph jitters along with the rapid saccadic movements of our eyes-looking up, looking down, blinking to keep up with its fluttering displacements.

Lassry's digitally augmented photographs continue the project of MoholyNagy's New Vision as a proprioceptive animation of our vision. A 'vision in motion' is made manifest through the involuntary somatic movements of 
our eyes and bodies striving to get a better grip on the image. We reposition ourselves, again and again - stepping back, to the side, then forward, tilting our heads and necks from one angle to another, or tentatively reach out to 'touch' the illusion. The kinesthetic demands of these pictures complicate Gregory's 'upwards' and 'downwards' model for solving optical illusions. We pause and stall, unsure of how to decipher their indefinite blur, well aware that any photograph we see today could be analog or digital, Photoshopped or not. What is at stake in recognizing this difference? I assert, along with Lassry, that while the actual difference is incidental, our growing consciousness of the multiplicity of the digital is tripping up our facility to settle on a 'top-down' interpretation that can conclusively 'place' the image. With nearly all photographic images passing through the computer-whether they are taken, viewed, or disseminated through its virtually networked screen - the digital insinuates itself as an immanent interference pattern. Like the fallible observer of $19^{\text {th }}$-century philosophical toys, our vision is permanently dilated through this extended realm of illusion. The ubiquity of digital activity in our everyday lives is aggressively querying how our eyes and minds organize - or, put differently, how we cognitively map-our place in the world as it is mediated by the endlessly permutational space of the screen.

Invoking this idea of a 'cognitive map' brings us back to Jameson. For Jameson, an aesthetic of cognitive mapping resists the disorienting effects of a spreading global capitalism. It serves as a spatial analogue to Louis Althusser's theory of ideology as 'the imaginary relationship of individuals to their real conditions of existence'. ${ }^{6}$ My usage of the term reverts to its more mundane definition as the mental picture we form to represent and locate ourselves in space-a definition to which Lassry subscribes. 'I'm interested in the viewer making mental pictures', the artist states, or 'how an image can travel, starting with something that you look at then becoming this echo of a mental picture that keeps moving around in your head'. ${ }^{37}$ As we have seen, the 'symbolic form' of perspective is one such

36 See Jameson, 'Cognitive Mapping', pp. 347-357. Jameson threads his thoughts on cognitive mapping throughout his writings on postmodernism, applying a figure of spatial analysis to the social structure of a given historical moment. He associates, for example, the first stage of capitalism with the 'logic of the grid' and the 'geometrical and Cartesian homogeneity' of perspectival space (p. 349); the second stage with the imperialism of an industrial modernism enmeshed with 'the new global relativity of the colonial network'; and the third, late stage with the breakdown of the grid in postmodern hyperspace and the insertion of the subject into a 'multidimensional set of radically discontinuous realities' (p. 351). As a consciousness-raising aesthetic, cognitive mapping invents new literary and artistic forms to intervene in the collective incapacity for representation wrought by the postmodern spatialization of capital.

37 Lassry, 'Interview with Brendan Fowler', p. 61. 
mental picture for bodily orientation. It, too, is a historically contingent ideology — an 'imaginary relationship' - that produces a 'sense of space' that has over-determined our 'sense of the world'.$^{8}$ While this criticism of perspective is by no means new, it is my contention that the merging of photographic space with the computational space of the digital screen is excavating the latent ground of other spaces that have resided unseen within the photograph's picturing of the world. Lassry's work involves the viewer in investigating this nascent ground. His 'nervous pictures' are rooted in our seeing bodies reacting to the ambiguous spatial possibilities within the photograph. They chart out mobile paths for our looking, viscerally displacing us from position to position, view to view. Untethered as subjects of perspective, we can attune ourselves to the surprising spaces that open up within the photograph. Its buried topological contours surface as we come to perceive the position of our bodies in perpetual relation to some other position in which we might be.

In this bind between vision and proprioception, to 'see the world with entirely different eyes' is to make these moving 'mental pictures' of the progressively blurring boundary between virtual and physical space as they meet in the photograph's branching topologies. One difference between the analog and the digital that debatably does matter in this perceptual mapping process is that, when seen on the computer, Lassry's pictures are flattened in multiple ways on the unifying plane of the digital screen. They are image files compressed, stored, and randomly resized like so many pixelated scraps. But this segues into another set of issues about quantity, scale, and information that a generation of 'Post-Internet' photographers - of whom Lassry is but a precursor-are dealing with in diverse ways..$^{39}$ It is certain, though, that unexpected paths are unfolding through which our eyes and minds can move. The next question to ask, then, positioned as we are on this evolving ground of contemporary photographic space, is: How are we oriented in the world now? And towards what?

38 Panofsky, Perspective as Symbolic Form, p. 34.

39 Although the term 'Post-Internet' periodizes a range of practices across media and genres, artists who notably work within the expanded image culture of the internet include Michele Abeles, Katja Novitskova, Artie Vierkant, and many of the artists in the show 'Ocean of Images: New Photography 2015' at the Museum of Modern Art in New York, NY. Forging an 'Internet-aware' aesthetic, these artists combine sculpture, analog photography, born-digital images, and the fluid 'online' and 'offline' presentation and distribution of their work at galleries, through books and PDFs, and on the Internet. See Vierkant, 'The Image Object Post-Internet', <http://jstchillin. org/artie/vierkant.html> and Katja Novitskova, 'Post Internet Survival Guide'. <http://katjanovi. net/postinternetsurvivalguide.html>. (Both accessed 5 August 2016). 


\section{Bibliography}

Alberti, Leon Battista. ([1435] 1956). On Painting, translated by John R. Spencer. New Haven, CT: Yale University Press.

Bollen, Christopher. (2011). 'L.A. Artworld: Elad Lassry'. Interview Magazine, (December/January): http://www.interviewmagazine.com/art/la-artworld/. (Accessed 5 August 2016).

Crary, Jonathan. (1990). Techniques of the Observer. Cambridge, MA: MIT Press.

Damisch, Hubert. (1994). The Origin of Perspective, translated by John Goodman. Cambridge, MA: MIT Press.

Friedberg, Anne. (2006). The Virtual Window: From Alberti to Microsoft. Cambridge, MA: MIT Press.

Galassi, Peter. (1984). Before Photography: Painting and the Invention of Photography. New York: The Museum of Modern Art.

Gombrich, Ernst. (1982). The Image and the Eye: Further Studies in the Psychology of Pictorial Representation. London: Phaidon.

Gregory, Richard L. (1997). Eye and Brain: The Psychology of Seeing, Fifth Edition. Princeton, NJ: Princeton University Press.

Gunning, Tom. (2008). 'What's the Point of an Index? Or Faking Photographs'. In Still/Moving: Between Cinema and Photography, edited by Karen Beckman and Jean Ma. Durham, NC: Duke University Press, pp. 39-49.

Holmes, Oliver Wendell. (1859). 'The Stereoscope and the Stereograph'. The Atlantic (June): http://www.theatlantic.com/magazine/archive/1859/o6/the-stereoscopeand-the-stereograph/303361/. (Accessed 5 August 2016).

Jameson, Frederic. (1990). Postmodernism, or the Cultural Logic of Late Capitalism. Durham, NC: Duke University Press.

— . (1988). 'Cognitive Mapping'. In Marxism and the Interpretation of Culture, edited by Cary Nelson and Lawrence Grossberg. Urbana, IL: University of Illinois Press, pp. 347-357.

Lassry, Elad. (2015). 'Photography and Composition', Hammer Museum, Los Angeles, CA. 28 June 2015. Artists Panel with Thomas Demand, Elad Lassry, Catherine Opie, and Russell Ferguson.

—_ (2014). 'Elad Lassry in Conversation with Jörg Heiser'. In Elad Lassry, edited by Alessandro Rabottini. Milan: Mousse Publishing.

- (2012). 'Interview with Ryan Trecartin'. Interview Magazine (September): 140-144.

- (2011). 'On Display', interviewed by Mark Godfrey. Frieze 123 (November/ December): https://frieze.com/article/display. (Accessed 5 August 2016).

—. (2010). 'Interview with Brendan Fowler'. ANP Quarterly 2, No. 5 (November): $54-67$. 
Lippit, Akira Mizuta. (2012). 'One, or Several (Blue) Wolves?' In Elad Lassry, edited by Elad Lassry and Toshio Shiratani. Tokyo: Rat Hole Gallery, pp. 131-135.

Manovich, Lev. (2013). Software Takes Command. New York: Bloomsbury.

Mendelson, Bert. (1990). Introduction to Topology: Third Edition. New York: Dover. Moholy-Nagy, László. (2005). The New Vision: Fundamentals of Bauhaus Design, Painting, Sculpture, and Architecture, translated by Daphne M. Hoffmann. New York: Dover Publications.

—. (1969). Painting, Photography, Film. Cambridge, MA: MIT Press.

—. (1947). Vision in Motion. Chicago, IL: Paul Theobald, 1947.

Novitskova, Katja. (2010). 'Post Internet Survival Guide'. Available at: http:// katjanovi.net/postinternetsurvivalguide.html. (Accessed 5 May 2016).

Panofsky, Erwin. (1996). Perspective as Symbolic Form, translated by Christopher S. Wood. New York: Zone Books.

Snyder, Joel. (1980). 'Picturing Vision'. Critical Inquiry 6, no. 3 (Spring): 499-526.

Vierkant, Artie. (2010). 'The Image Object Post-Internet'. Available at: http:// jstchillin.org/artie/vierkant.html. (Accessed 5 May 2016).

Weeks, J.R. (2002). The Shape of Space. New York: Marcel Dekker.

\section{About the Author}

Jennifer Pranolo is a Visiting Assistant Professor in Visual Studies at Haverford College. She received her PhD in Film and Media from the University of California, Berkeley and was previously a Critical Studies Fellow at the Whitney Independent Study Program. Her work on film and digital aesthetics has appeared in Screen, Film Quarterly, and elsewhere. Her current research focuses on identity and digitality in contemporary art, cinema, and computational culture. 
